\title{
Grundtvigs prædiken den 31. juli 1825
}

\author{
Niende Søndag efter Trinitatis. \\ (Aften-Sang).
}

Epistelen. 1. Corinth. 10. Cap. 6.-13.

Men disse ting ${ }^{1}$ ere blevne vore forbilleder, at vi skal ikke have lyst til onde ting, ligesom og de havde lyst. Bliver ey heller afguds-dyrkere, som nogle af dem; som skrevet er: folket satte sig ned at æde, og at drikke, og stod op at lege. Lader os ey heller bedrive horerie, som nogle af dem bedreve horerie, og faldt paa een dag tre og tive tusinde. Lader os ey heller friste Christum, som og nogle af dem fristede ham, og bleve ødelagte af slanger. Knurrer ey heller, som og nogle af dem knurrede, og bleve ødelagte af forderveren. Men alle disse ting skede dem, som forbilleder; men det er skrevet os til advarsel, paa hvilke verdens sidste tider ere komne. Derfor, hvo som synes at staae, see til, hand ikke falder. Eder er ingen fristelse paakommen, uden menniskelig; men Gud er trofast, som skal ikke lade eder fristes over eders formue; men skal og giøre udgangen med fristelsen, at I det kan taale. ${ }^{2}$

[Her ifølge Frederik Vs bibel; teksten i Christian VIIs bibel, som Grundtvig brugte, adskiller sig ikke herfra i ordlyden.]

1. De første 5 vers af 10 . Cap. lyder: "Men jeg vil ikke dølge for eder, brødre! at vore fædre vare alle under skyen; og de gik alle igiennem havet; og de ere alle døbte til Moses, i skyen, og i havet; og de aade alle den samme aandelige mad; og de drak alle den samme aandelige drik; thi de drak af den aandelige klippe, som fuldte dem; men klippen var Christus. Men Gud havde ikke behagelighed til de fleste af dem; thi de ere nedslagne i ørken."

2. De 4 følgende vers lyder: "Derfor, mine elskelige! flyer fra afguds-dyrkelsen. Jeg taler som til forstandige; dømmer I, det jeg siger: Velsignelsens kalk, som vi velsigne, er den ikke Christi blods samfund? det brød, som vi bryde, er det ikke Christi legemes samfund? Thi eet brød, eet legeme ere vi mange; thi vi ere alle deelagtige i det eene brød." 


\section{Jesu velsignede Navn!}

Det er, Chr[istne] V[enner], Guds Folk i det Gl. Testamente, Israels Børn i Ørken, Apostelen taler om, og vidner i Herren, at de ere vore For-Billeder, at Guds øiensynlige Førelser med dem betegne Hans usynlige, aandelige Førelser med os, Hans Folk i det Ny Testamente, som ere kaldte efter Sønnens, vor Herres Jesu Christi Navn. Udførelsen af Ægypten ved Moses ligner han saaledes ved vores Udfrielse fra Mørkets Magt ved Jesum Christum, den underlige Frelsning giennem Vandet, i det røde Hav, ligner han ved Daaben, det store, underfulde Gienfødelsens og Fornyelsens Bad, som skeer ved den Hellig-Aand, det Himmel-Brød, hvormed de mættedes, og Vand-Springet af Klippen, hvormed de lædskedes i Ørken, ligner ${ }^{1}$ han ved det Brød, vi bryde, og Kalken, vi velsigne, som vor Herres Jesu Christi Legems og Blods Samfund, vor Deelagtighed i ham, som siger: jeg er det Brød, som kom ned af Himmelen, jeg er det Livsens Brød, hvo som kommer til mig, skal ikke hungre, og hvo som troer paa mig, skal aldrig tørste, hvo som drikker af Vandet, jeg vil give, skal ikke tørste evindelig, thi Vandet, jeg giver ham, skal blive en Kilde $\mathrm{i}$ ham, som springer til et evigt Liv. Dette er Lignelsen, som Apostelen fremstiller, ei til ØiensLyst, men til Formaning og Advarsel, i det han lægger os paa Hjerte, at det gamle Guds Folk, som Herren beviste saamegen Naade, frelste med en høi Arm af Fiendens Haand, og opholdt paa underlige Maader, gik dog for Største-Delen glip ad Hans Velbehag, og kom ikke til Hans Hvile, kom ikke til Landet, Gud lovede Abraham. Han havde ikke Behagelighed til de Fleste af dem, thi de bleve nedslagne i Ørken, og Grunden, siger han $\mathrm{i}$ Dagens Epistel, var den, at de toge Guds Naade forgiæves, deres Hjerte var ikke trofast mod Gud, de sloge tilbage som en falsk Bue. Ja, siger han, ogsaa deri skal vi see os i Speil, og ej have Lyst til det Onde, som de havde Lyst, men skye deres AfgudsDyrkelse, Horerie, Formastelse og Trodsighed, at det skal ei gaae os, som det gik dem, at Guds Naade og alle Hans underlige Gierninger skal ikke være spildte paa os, som de jo er, naar vi ei blive Ham behagelige, thi Livet er i Hans Velbehag, Hvilen, den

1. Her er i marginen tilføjet: (hellige Nadvere). 
store Hvile er kun dem beredt, hvis Hjerte er trofast mod Ham, hvis Fødder vige fra det Onde, hvis Lyst er at giøre Hans Villie, hvis Hug staaer til Hans Helligdom, hvis Borgerskab er i Himlen, og som taalmodige vente paa Hans Salighed!

Sandelig, her fattes ei Anledning til store Betragtninger for os, der end ere paa Veien, vandre i Ørken, hvor vi hvert Øieblik fristes til at vende om i Hjertet til Ægyptens Kiød-Gryder, til Verdens Lystighed, som sætter sig ned at æde og drikke og staaer op at lege, og kalder det med Rette sin Guds-Dyrkelse, fordi dens Bug er dens Gud, Øiens-Lyst, Kiøds-Lyst og Overdaadighed dens Himmel!

Allerede derfor kan vi, som Christne, aldrig tænke, det er overflødigt at agte paa Apostelens Formaning: bliver ikke Afguds-Dyrkere, som Nogle af Hine; thi vi veed, at alt Hjertets Utroskab mod Herren, al Kiærlighed til det, som ikke er af Faderen, men af Verden, det er i Hans Øine, som seer paa Hjertet, Afguderie; vi veed, der dandses om Guld-Kalven, hvergang Hjertet fryder sig over Mammon, og hvergang det søger sin Glæde i kiødelig Vellyst, vi veed, det er Afvigelse fra Herren, hvergang vor Lyst er ikke til Hans Lov, men til at vandre vore egne Veie! O, derfor, Chr. V., lad os ikke være Afgudsdyrkere men tjene vor Gud, uden Svig, følge vor Frelser og Ledsager uden Knur, paa den tornede, den trange, men dog ønskelige Vei, Han haver banet os giennem Ørken til de Levendes Land, det Land med Melk og Honning, med Alt, hvad Aanden kalder lifligt, hvad Hjertet kalder sødt, og hvad Engle-Tunger, ja, hvad Ordet, som er Gud, hvad den Eenbaarne selv kalder saligt!

Lad os det, lad os, som de, der ere døde for Synden og opreiste med Christo, vandre i et nyt Levnet, dyrkende ivrig i Tro og Haab og Kiærlighed den eneste sande Gud, Fader, Søn og Hellig-Aand, som vi i Daaben gienfødtes til at kiende og bekiende, og som vi i Nadveren beredes til at skue, Ansigt til Ansigt; da kan vi rolig høre paa Verdens Spot, rolig, med sunde og sindige Ord giendrive dens bespottelige Tale, hvormed den sigter os for Afguds-Dyrkelse, sigter os stærkere, jo mere uopløselig vi knytte os til ham, i hvem det behagede Faderen, at al Guddoms-Fylde skulde legemlig boe, og som derfor haver vidnet, at kun giennem Ham gaaer Veien til Faderen, kun giennem Ham, som er 
selv den levende Vei, den lysende Sandhed, det sande, det evige Liv!

Ja, christne Venner! ere vi i Sandhed opreiste med Christo, saa Hjertet kun har Øie paa de Ting heroventil, hvor Christus sidder ved Guds høire Haand, da kan vi rolig høre paa Fiendens gamle, bespottelige Løgn, at det er Afguds-Dyrkelse, naar vi bøie Knæ i Navnet, som er over alle Navne, og tilbedende bekiende, at Jesus Christus er vor Herre, til Gud Faders Ære; men dog siger Apostelen i Dagens Epistel: hvo som staaer, see vel til, at han ikke falder, og sandelig, det er en Formaning, vi aldrig maae glemme, aldrig kan glemme, uden at snuble, og sandelig, er der nogen Deel af Herrens Menighed, der især trænger til at see sig for, da er det os, til hvem, efter Textens Ord, ret aabenbar Verdens sidste Tider ere komne. Ja, vi maae vel sige, at os er en Fristelse paakommet meer end menneskelig, skiøndt ikke over den Formue, Gud giver, ei anderledes, end at Gud baade kan og vil giøre en Udgang paa Fristelsen, som vi kan taale; ja, Fristeren gik mægtig, gik blændende, som en Lysets Engel, over Jorderige, og hans Tjenere vare som Retfærdigheds Tjenere, falske Apostler og svigefulde Arbeidere, som forvandlede sig til Christi A postler, og Kirken vaklede paa sin Grundvold, saa Herrens Menighed maa bekiende med Asaph: der fattedes lidet i, at mine Fødder bøiede af Veien, hardtad Intet $i$, at mine Trin vare afgledne. Hvad Apostelen Peder prophetisk forkyndte: der skal være falske Lærere iblandt eder, som derhos skal indføre fordærvelige Secter, og nægte den Herre, som dem kiøbde, og Mange skal efterfølge deres Fordærvelighed, formedelst hvilke Sandhedens Vei skal bespottes, det er øiensynlig skedt i vore Fædres og i vore Dage, da det hardtad over al Christenheden udraabdes for Afguderie at tilbede Jesum Christum, som Gud med Faderen af Evighed. Vist nok er den Beskyldning ikke ny, nei, den er tvertimod saa gammel som den christelige Kirkes Troes-Bekiendelse, saa gammel som Verdens aabenbare Fiendskab mod Herren; thi ligesom Jøderne sagde til Ham: vi stene dig ikke for dine gode Gierninger, men fordi du, som er et Menneske, giør dig selv til Guds Søn, kalder Gud din egen Fader og giør dig Gud lig! saaledes er det ogsaa det gamle Skrig af Kirkens Fiender, af Jøder, Tyrker og Hedninger, at de Christne, som grove AfgudsDyrkere, tilbede et Menneske, og det et Menneske, der døde 
som en Misdæder paa Korset, og om hvem de løgnagtig sige, at Han opstod igien fra de Døde, opfoer til Himmelen, sidder ved Gud Faders høire Haand og skal derfra igien komme, at dømme Levende og Døde! Nei, sandelig, det er ei nyt, for hvem der veed, hvad Herren maatte lide, fordi han kom, ei i sit eget Navn til Dom, men i sin Faders Navn til Frelse og Forsoning, for hvem der veed, hvad Christi Kirke og Menighed har maattet høre, bære og lide, naar Fienderne larmede og Haderne løftede Hovedet, sigende: kommer og lader os udslette dem til ikke at være et Folk, at Israels, ja, at Christi Navn skal ikke mere ihukommes; thi sandelig, Kirken maa klage med Psalmisten: vee mig, at jeg var fremmed hos Mesech og haver boet blandt Kedars Pauluner, længe boede min Sjæl hos den, som hader Fred, jeg er fredsommelig, men saasnart jeg taler, da gribe de til Vaaben, da fare de i Harnisk. Saa var det, Venner, alle Dage, saasnart Christi Kirke og Menighed talede, opløftede sin Røst til at bekiende sin Tro og sit Haab, det salige Haab til Guds og Frelserens Jesu Christi Herligheds Aabenbarelse, da havde den Fiender paa Halsen, som spottede, som stormede, som rasede imod den. Det er da ikke Nyt, men det var nyt, at de, der nægtede den Herre, som dem kiøbde, at de, der kaldte det Afguderie at tilbede Jesum Christum som sand Gud med Faderen, at de vilde kaldes Christne, at de vilde føre Ordet i den Kirke, de forhaanede, den Kirke, de bestormede, at de turde paastaae, det var ei blot afgudisk, men ogsaa uchristeligt at tilbede og paakalde Jesum Christum, at de turde paastaae, det streed mod Jesu Christi egen Lærdom, mod den sande Christendom, at de, med ærligt Ansigt, vidnede for Menigheden, at hvem der ret forstod sin Bibel, kunde læse den i Grund-Sproget, og kiendte den østerlandske Talebrug, det gamle Billed-Sprog, de saae det grandt, at Jesus Christus ingenlunde vilde troes paa, æres og tilbedes som vor Gud, men kun troes og følges som en forstandig Lærer og dydig Mand; ja, det var Nyt i Christenheden, det var et hemmeligt Anslag mod Herrens Folk, et Skalke-Raad imod Hans Skjulte; det kalder jeg en Fristelse meer end menneskelig, for Menigheden, for dem, der hverken havde Kundskab eller Indsigt til klarlig at see, hvor grovt man løi, hvor falskelig man vidnede, og den Tvivl-Raadighed, hvori de Christne derved nedsank, skiøndt den var Synd, vil Gud i Naade forlade dem, som Han 
forlod vore første Forældre den Tvivl-Raadighed, hvortil Slangen forførde dem, og Han vil igien opreise dem i Troen, som Han opreiste det faldne Menneske i den anden Adam, i sin eenbaarne Søn, vor Herre Jesus Christus.

Es. 40 Ja, trøster, trøster mit Folk! skal eders Gud sige, taler kiærlig til Jerusalem, og raaber til den, at dens Strid er endt, thi dens Misgierning er forsonet, thi den haver faaet dobbelt af Herrens Haand for alle dens Synder; alt Kiød er Græs, og al dets Fromhed er som en Blomst paa Marken, Græsset henvisner, Blomsten affalder, naar Herrens Veir blæser derpaa, Græsset henvisner, Blomster affalder, men vor Guds Ord bliver evindelig. Du, som bærer Zion Budskab, stig du op paa et høit Bjerg, du, som bærer Jerusalem Budskab, løft Røsten med Vælde, løft den, frygt ikke, siig til Judæ Stæder: see, eders Gud! Røsten raabe i Ørken: rydder Herrens Vei, baner vor Guds slagne Vei paa den jævne Mark, hver Dal skal ophøies, hvert Bjerg og hver Høi skal fornedres, og det Krumme blive lige, det Knudrede glat, og Herrens Herlighed skal aabenbares, og de, alt Kiød tillige, skal see det, som Herrens Mund haver talet!

Chr. Venner! er det eder en mørk Tale, veed I det ikke, hvorledes Herren trøster sit Folk, og giør Ende paa Tvivl-Raadigheden, aabenbarer sin Herlighed, saa de maae alle see det, Store og Smaa, Vise og Vankundige, at Han, at Jesus Christus er vor Gud, de Christnes Gud med Æren, og til Hans Faders Ære, saalænge Verden staaer; veed I det ikke, hvorledes Herren beskiæmmer dem, der sige, det er uchristeligt og afgudisk at tilbede ham, at ære Sønnen, som man ærer Faderen, og kalde ham sin Gud; veed I det ikke, hvorledes Han haver fanget de Trædske i deres egen Snare, i Snaren, de spændte i hans Kirke for hans Menighed, hvorledes de selv ere faldne i Graven, de grov, nedfarne til de Uomskaarne, til alle Kirkens aabenbare Fiender; veed I det ikke endnu, da hører mig nøie, da hører, hvorledes Herren har lært mig at trøste Herrens Folk og tale kiærlig til Jerusalem, da hører, hvad jeg nu har lært at svare dem, der kalde sig Christi Apostler, Jesu Christi Tjenere, og vil dog røve Ham Hans Guddoms-Ære, røve Hans Legeme, som er Hans Menighed, dens Hoved i Himlene, og dermed dens visse Haab, dens evige Trøst. Eller veed I det alt, vidste I det maaskee længe for jeg, som, efterat have lidt Skibbrud paa Barndommens Tro blev fundet 
som et Lig paa den nøgne Strandbredd, og kunde længe ei ret besinde, hvor jeg var, da jeg vaagnede i Kirken, indbildte mig længe, at jeg havde været langt borte $\mathrm{i}$ fremmede Lande, og var med Pilegrims-Staven halv vandret, halv baaret tilbage til Hjemmet, til Kirkens Moder-Skiød, kunde længe ei forstaae, at det var Altsammen en Drøm, en gruelig Drøm, fordi jeg glemde Aften-Bønnen, Aften-Psalmen, og hvoraf jeg vaagnede, da Bede-Klokken slog, og jeg, endnu halvsovende, istemde:

Lov og Tak og evig Ære

Skee dig, o, Guds hjerte Søn,

Som en Tjener vilde være,

Kommen ud af Davids Kiøn!

Søde Jesu! lær du mig,

At jeg vandrer rettelig,

Og i dine Fodspor træder,

Ja, udi din Vei mig glæder!

Lad mig aldrig dig forsage,

Om end Kors og Kummer mig

Skal i denne Verden plage,

Men at jeg dog inderlig

Elsker dig indtil min Død,

Og forsøder al min Nød

Med din Fødsel, Død og Smerte,

Tag dem aldrig fra mit Hjerte!

$\mathrm{Nu}$ først seer jeg det ret, det var en Drøm, thi Daabens Naade og Nadverens Velsignelse var det jo, som traadte i Kraft, der jeg vaagnede i Troen, og veed I det, da veed I, hvad jeg har at sige, men vil dog glæde eder med mig, at jeg har ogsaa lært det, hvad sikkerlig Mange behøve at paamindes om, for at komme ihu, de er Christne.

Saa svarer jeg da dem, der sige, det er baade afgudisk og uchristeligt at kalde Jesus Christus Gud med Faderen og at tilbede Ham. I tage mærkelig feil; i det Mindste, naar I sige, det er uchristeligt; thi det er eder, saavelsom mig, det er os alle vitterligt, at saalænge der var Christne til, saalænge var der ogsaa Folk, som døbtes i Navnet Faderens, Sønnens og den Hellig- 
Aands, saalænge var der ogsaa Folk, som bekiendte, at Jesus Christus var den Guds eenbaarne Søn, Gud med Faderen, paa hvis Ord de lod dem døbe, i hvis Navn de knælede, i hvis Navn de ved Daaben annammede Guds Aand med Syndernes Forladelse, $\mathrm{i}$ hvis Legems og Blods Samfund de fandt det evige Liv, som Guds Naadegave i ham, i Christo Jesu, vor Herre; see, det er, hvad I ikke kan nægte uden at blive til Latter for hinanden og for Menigheden, det er, hvad Kirkens Fiender bevidne ligesaa høirøstet, som dens Venner, det er den apostoliske Troes Bekiendelse, som er beseiglet med alle deres Blod, som udgiød det for vor Herres Jesu Christi Vidnesbyrd, det er den Troes-Bekiendelse, som vi endnu finde $\mathrm{i}$ alle christne Menigheder, som ogsaa for eder aflagdes, da I annammede Daaben, som et Igienfødelsens og Fornyelsens Bad ved den Hellig-Aand, dette er Bekiendelsen, I selv have tilegnet eder, dersom I ikke, ved at foragte Herrens Bord, selv have udelukt eder af Hans Menighed. Deri fare I da øiensynlig og storlig vild, at I sige, man kan være Christen, uden at ære Sønnen og den Hellig-Aand ligesom Faderen, med guddommelig Tilbedelse, med Lov og Priis, som Gienløseren og Gienføderen til et evigt Liv, ja, som GuddomsLyset og Guddoms-Livet selv, der oplyser og opliver, forbinder og forener den ganske Menighed til eet Legeme og een Aand i Christo Jesu vor Herre!

Vel hører jeg, I sige, det skal staae i Bibelen, at denne vores, at denne alle Christnes Troes-Bekiendelse er falsk, men det er jo aabenbar Daarskab at tale saa, thi hvad der end staaer i Bibelen, saa er det jo lige vist og lige unægteligt, at den Troes-Bekiendelse, de Christne til alle Tider, i alle Menigheder har aflagt, den og ingen anden er de Christnes Troesbekiendelse, saa hvem der. vil nægte det, var det end en Engel af Himmelen, han lyver grovt. Eller mener I kanskee, de Christne meende ikke, hvad de sagde, udgav sig kun falskelig for at troe paa Gud Fader, Søn og HelligAand, for Jesu Christi dyrekiøbte Tilbedere; mene I det, da staaer det dog vel ikke i Bibelen, og sæt, det stod i al Verdens Bøger, saa vidste dog enhver af os, som virkelig har den Tro, han bekiender, at det var Løgn, og I kan selv ikke nægte, at da den Tro blev høiest og frimodigst bekiendt, da skulde man just ikke fristes til at bekiende Tro paa Jesum Christum, naar man ikke havde den, thi Ære, Liv og Gods, det var, hvad Bekiendelsen 
kostede. Eller mener I endelig kun, at de Christnes Troes-Bekiendelse strider imod Bibelen, da er det vist nok mere sagt, end I kan bevise, men sæt, I kunde, hvad havde I da dermed andet beviist, end at Bibelen var i Grunden ogsaa uchristelig, saa de Christne havde begaaet en stor Feiltagelse, ved at beraabe sig paa den, og Morten Luther et slemt [a] Bedragerie, da han paastod, at [de Christnes] Bibelen paa det Allerklareste stadfæstede de Christnes ældgamle, uforanderlige, apostoliske Troes-Bekiendelse, og lærde os, som Lyset i Kirken, tillige at skille den fra alle Pavedommets Vildfarelser, hvori den var begravet. Ja, det er aabenbart, at naar I kunde giøre eders Mesterstykke, og klarlig bevise, at Bibelen streed imod Kirkens Bekiendelse, da havde I kun skildt Kirken ved hvad den stedse kaldte sit Lys men christeligt blev det ligefuldt til Verdens Ende, at tilbede Jesum Christum som Gud og Frelser, uchristeligt, jødisk, tyrkisk og hedensk blev det ligefuldt at kalde denne Tilbedelse afgudisk, at nægte Jesu Guddom, og dermed nødvendig tillige baade Daabens og Nadverens saliggiørende Kraft, der kun er til for Jesu Christi troende Tilbedere! Vil I altsaa blive ved at paastaae, det er Afguderie, da skal I nødes til at [indrømme det at] paastaae, at Christendommen selv, den eneste sande, virkelige Christendom, [b] som er troet og bekiendt i Verden, som har gjort alle de Gierninger, vi kalde christelige, at den lige fra Begyndelsen var og er til sine Dages Ende, et aabenbart Afguderie, og med denne Paastand kan I dog umuelig længer ville hedde Christne da I dermed selv bekiendte, I vidste godt at I var Afgudsdyrkere, men vilde blive ved at være det.

Skal jeg endnu blive ved at tale til disse, nei, naar det er beviist, de er ei Christne, men vi er det, saasandt vi virkelig troe hvad vi bekiende, da vender jeg mig til Menigheden sigende: At Christendom ikke er Afguderie, det veed I, som Christne, thi have I Sønnen, da have I ogsaa Faderen, men staae I kanskee end tvivlraadige og tør ikke annamme Sønnen, udenom hvem der kommer Ingen til Faderen, saa hører dog Vidnesbyrdet af Skaren, som Ingen kan tælle, af dem der i Nød og Død vidnede, at de ved Tro paa Jesu Christi Guddom annammede Guds Fred, Guds Kraft og Guds Kiærlighed, betragter i Stephanus de mange tusende Vidner, som vidste det gjaldt deres Liv [c] i denne Verden, dersom de bekiendte Jesu Christi Guddom, og gjorde det 
dog, havde dog baade Kraft til at giøre det frimodig og Kiærlighed til at giøre det med Glæde, og at altsaa de ærligste, de sandhedskiærligste Mennesker i Verden, som heller vilde døe, end dølge den Tro, at de maatte have været de ublueste Løgnere, dersom Jesus Christus var en Afgud, thi at man ikke ved Afguderie faaer Lyst til at giøre den sande Guds Villie, som skabde Himlen og Jorden, det kan vi alle forstaae.

Dog er et saadant, menneskeligt Vidnesbyrd end stort, saa er dog Guds Vidnesbyrd større, og haver han ikke klarlig vidnet for Jesus Christus, i det Forsyn der altid var over hans Kirke, den Kirke hvor man ærede Sønnen som Faderen, hvor Jesu Christi Guddoms-Priis gienlød fra alle Munde - Hvad maatte det være for en Gud, ligegyldig ved Løgn og Sandhed, ligegyldig ved Menneskens Slægt, som ei blot skulde taale, at denne Kirke bestod paa Jorden, til Trods for alle sine Fiender, men at den havde de ærligste, [d] kiærligste Mennesker at fremvise mellem sine Sønner og Døttre, at den skulde derved aabenbar beskiæmme sine Fiender som jo maatte være den sande Guds Tjenere dersom den var et Afguds-Tempel.

Saaledes er det aabenbart, er Jesus ikke Gud, da var der ingen Gud, men er der ingen Gud, da er der heller ingen Afgud, og da Jesus Christus dog haver virket og virker guddommelig paa alle dem der af Hjertet troe og bekiende Hans Guddom, saa er Han aabenbar den sande Gud, og havde han ikke selv sagt os, at Faderen var større end Han, saa han var kun Gud med Faderen, da maatte vi ingen anden Gud tilbede end ham, men nu skal vi, paa hans Ord tilbede Gud Fader, Gud Søn og Gud den HelligAand visse paa, at dermed ere vi bevarede fra alt Afguderie, og beredes til de Helliges Arvedel i Lyset, ja til Forening i Kiærlighed med Ham, af Hvem og ved Hvem og til Hvem alle Ting ere, høilovet i Evighed

Amen! i Jesu Navn Amen! [Slutningen - mærket [a-d] - meddelt ved Kaj Thaning.] 